\title{
Percentiles of serum uric acid and cardiometabolic abnormalities in obese Italian children and adolescents
}

\author{
Rosa Luciano ${ }^{1,2}$, Blegina Shashaj ${ }^{2}$, MariaRita Spreghini ${ }^{3}$, Andrea Del Fattore ${ }^{2}$, Carmela Rustico ${ }^{3}$, \\ Rita Wietrzykowska Sforza ${ }^{3}$, Giuseppe Stefano Morino ${ }^{3}$, Bruno Dallapiccola ${ }^{2}$ and Melania Manco $2,4^{*}$ (D)
}

\begin{abstract}
Background: To investigate the association of serum uric acid (SUA) with cardiometabolic abnormalities in Caucasian overweight/obese children ( $<10$ years of age) versus adolescents ( $\geq 10$ years of age) by drawing age and gender specific percentiles of uric acid.

Methods: Cross-sectional evaluation of 1364 Caucasian overweight/obese patients (age 4.1-17.9 years; 726 males, 53\%; 560 children, 41\%).

Results: SUA levels were significantly lower in children than in adolescents $(4.74 \pm 1.05 \mathrm{vs} .5 .52 \pm 1.49 \mathrm{mg} / \mathrm{dl}$, $p<0.001)$ and peaked in 12-14 years-old boys and 10-12 years-old girls.

In children with levels of SUA in the highest quartile $(N=75,13 \%)$, OR for high triglycerides was $4.145,95 \% \mathrm{Cl} 1$. 506-11.407 ( $p=0.009)$. In adolescents with SUA in the highest quartile $(N=274,34 \%)$, ORs for insulin resistance was 2.399 (95\%Cl 1.4-4.113; $p<0.001$ ); for impaired fasting glucose 2.184 (95\% Cl 0.877-5.441; $p=0.07$ ); for impaired glucose tolerance 2.390 (95\% Cl 1.405-4.063; $p=0.001)$; and for high triglycerides 1.8, $(95 \% \mathrm{Cl} 0.950-3.420 ; p=0.05)$. Multivariable random-effect linear regression models demonstrated that waist circumference and age $(p<0.0001$ for both) are the variables most significantly predicting SUA levels, followed by triglycerides $(p=0.005)$ and $2 \mathrm{~h}$ glucose $(p=0.03)$ while HOMA-IR and BMI z-score did not predict SUA.
\end{abstract}

Conclusions: High uric acid is associated with metabolic abnormalities and particularly with waist circumference very early in childhood.

Keywords: Cardiovascular disease, Childhood obesity, Insulin resistance, Metabolic syndrome, Uric acid

\section{Background}

Uric acid is the end-product of dietary and endogenous purine metabolism and results from the balance between hepatic production and renal excretion [1]. Serum uric acid (SUA) is an independent risk factor for atherosclerosis and cardiovascular disease (CVD) in adults [1-3] being associated in prospective studies with risk of developing metabolic syndrome (MetS), type 2 diabetes (T2D) and incident cardiovascular events [4].

\footnotetext{
* Correspondence: melania.manco@opbg.net

${ }^{2}$ Scientific Directorate, Bambino Gesù Children's Hospital, Rome, Italy

${ }^{4}$ Scientific Directorate, Research Unit for Multifactorial Disease, Bambino Gesù Children's Hospital, Rome, Italy

Full list of author information is available at the end of the article
}

In childhood and adolescence, SUA levels increase progressively from early childhood with body growth and plateau by $\sim 15-17$ years of age [5]. Concentrations in overweight and obese individuals are higher than in normal-weight peers [6,7] and are associated with insulin resistance (IR) [8], cardiometabolic abnormalities belonging to the MetS [7-9], greater waist circumference (WC) [10], incident hypertension [11], increased carotid intima-media thickness [12] and impaired flow mediated dilation [13].

Recent studies focused on the association between SUA and cardiometabolic risk in young obese patients of different age-groups including prepubertal children [13-15].

The current study aims at investigating the association of serum uric acid with insulin resistance, disturbed carbohydrate metabolism, dyslipidemia and waist circumference in 
obese Caucasian children as compared to adolescents by providing age and sex specific percentiles of uric acid in young obese Italians.

\section{Methods \\ Study population}

The study population includes 1364 Caucasian overweight/obese children and adolescents (age range 4.1817.93 years), referred by general practitioners to the Unit of Clinical Nutrition at the Bambino Gesù Children's Hospital between July 2012 and 2013 [16]. Patients underwent anthropometric measurements, laboratory evaluation of uric acid, fasting glucose and insulin, lipid profile, liver function tests, white blood cell count (WBC); and a standard oral glucose tolerance test (OGTT). No child had genetic, renal or endocrine diseases, chronic illness, consumption of drugs affecting growth and carbohydrate metabolism, family history of symptomatic hyperuricemia.

\section{Anthropometric evaluation}

Weight was measured with scales certified for medical use (90/384/EEC, SECA) with a precision of $50 \mathrm{~g}$ with children wearing minimal clothing and weight recorded to the nearest $100 \mathrm{~g}$. Height was measured with a Holtain stadiometer and recorded to the nearest $0.5 \mathrm{~cm}$. The average of two measurements was used. Children were classified as overweight/obese if BMI was 285 th percentile according to Italian references [17]. WC was measured midway between the superior border of the iliac crest and the lower margin of the ribs at the end of normal expiration.

\section{Biochemical assays and estimation of IR}

All the participants were asked to refrain from intensive physical activity in the 3 days prior to the study and were prescribed a standardized diet. Fasting blood samples were drawn after 8-12 h fast. Glucose and insulin levels were measured every $30 \mathrm{~min}$ starting from baseline up to $120 \mathrm{~min}$ following the OGTT ( $1.75 \mathrm{~g}$ of glucose $/ \mathrm{kg}$ body weight up to a maximum of $75 \mathrm{~g}$ ). The HOmeostasis Model Assessment of IR index (HOMAIR) was calculated as average on two blood samples $(-5$ and $0 \mathrm{~min})$ as [fasting glucose $(\mathrm{mg} / \mathrm{dl}) \mathrm{x}$ fasting insulin $(\mu \mathrm{U} / \mathrm{ml}) / 405]$. Insulin sensitivity index (ISI) was calculated as $[$ ISI $=10,000 / \sqrt{ }($ fasting glucose $\times$ fasting insulin $) \times($ mean glucose $\times$ mean insulin).

SUA, glucose, total cholesterol, high-density lipoprotein (HDL) cholesterol, triglycerides, alanine aminotransferase (ALT) and gamma-glutamyl transferase $(\gamma-G T)$ were measured by using commercial methods (ADVIA 1800 Chemistry System, Siemens Healthcare Diagnostic, Deerfield, IL). Serum insulin was analyzed by a chemiluminescent immunoassay method (ADVIA Centaur XP Immunoassay System; Siemens Healthcare Diagnostic, Deerfield, IL).

\section{Definition of metabolic abnormalities}

Dyslipidemia was diagnosed in the presence of at least one of the following conditions: value of cholesterol and/or triglycerides higher than the $95^{\text {th }}$ percentile and/or HDL cholesterol lower than the $5^{\text {th }}$ for age and sex according to the American Academy of Pediatrics [18]. The triglycerides to HDL-cholesterol ratio $>2.2$ was considered atherogenic $[19,20]$. Impaired fasting glucose (IFG) was defined as fasting glucose $\geq 100 \mathrm{mg} / \mathrm{dl}$; impaired glucose tolerance (IGT) as $2 \mathrm{~h}$ glucose $\geq 140 \mathrm{mg} / \mathrm{dl}$ following the OGTT. Insulin resistance was defined as HOMA-IR value $\geq 75^{\text {th }}$ percentile adjusted for age and sex according to reference value of HOMA-IR in the Italian population as described elsewhere [21]. Hyperuricemia was defined as SUA value $\geq 75^{\text {th }}$ percentile adjusted for age and sex.

\section{Statistical analysis}

Continuous variables were expressed as mean \pm standard deviation (SD) and categorical variables as number and percentage. Normal distribution was tested using the Kolmogorov-Smirnov test. Between-group comparison was performed by using the $x^{2}$ test for categorical variables and ORs calculated. The Mann-Whitney U test was used for comparison of continuous variables. Uric acid distribution was tabulated for the values corresponding to the 5th, 10th, 25th, 50th, 75th, 90th, and 95th percentiles. Correlations were sought by using the Spearman test and variables significantly associated with SUA (age, BMI Z-score, waist circumference, triglycerides, HOMA-IR and $2 \mathrm{~h}$ plasma glucose entered a multivariable random-effect linear regression models to evaluate the association of SUA with metabolic abnormalities.

Statistical analyses were performed using the SPSS 21 statistical package (SPSS, Chicago, IL, USA). A result with $p<0.05$ was considered statistically significant.

\section{Results \\ Description of the sample}

Table 1 describes the study population as a whole, age and sex subgroups. A total of 1364 overweight/obese patients were studied, 560 (41\%) children, 726 (53.2\%) were males. Dyslipidemia was diagnosed in $366(26.8 \%)$ patients; low HDL-cholesterol in 29 (2.2\%); high total cholesterol in 252 (18.5\%) and high triglycerides in 87 (6.4\%). Children affected by dyslipidemia were 162 out of $560(29 \%)$ and adolescents 204 out of 804 (25.4\%). Disturbed carbohydrate metabolism was found in 94 patients, [25 children out of $560(4.4 \%)$ and 69 out of 804 adolescents (8.6\%)]: 41 with IFG (3\%) and 53 with IGT (3.9\%). IR was found in 209 patients (15.3\%); 41 children (7.3\%), 168 adolescents (20.9\%). Table 2 reports SUA $(\mathrm{mg} / \mathrm{dl})$ in cases with metabolic abnormalities. Figure 1 show percentage of cases presenting with each metabolic 
Table 1 Characteristics of the study population

\begin{tabular}{|c|c|c|c|c|c|c|c|c|}
\hline & $\begin{array}{l}\text { Total } \\
1364\end{array}$ & $\begin{array}{l}\text { Male } \\
(N=726)\end{array}$ & $\begin{array}{l}\text { Female } \\
(N=638)\end{array}$ & $p$ value & & $\begin{array}{l}<10 \text { years } \\
(N=560)\end{array}$ & $\begin{array}{l}\geq 10 \text { years } \\
(N=804)\end{array}$ & $p$ value \\
\hline Age (years) & $10.74 \pm 2.70$ & $10.60 \pm 2.48$ & $10.83 \pm 2.93$ & 0.707 & Male & $290(39.9 \%)$ & $436(60.1 \%)$ & \\
\hline Weight (kg) & $60.64 \pm 18.74$ & $61.19 \pm 18.83$ & $60.00 \pm 18.63$ & 0.433 & & $45.98 \pm 9.21$ & $70.85 \pm 16.82$ & $<0.001$ \\
\hline Height (cm) & $147.22 \pm 14.06$ & $147.97 \pm 14.28$ & $146.36 \pm 13.77$ & 0.199 & & $134.76 \pm 9.31$ & $155.89 \pm 9.59$ & $<0.001$ \\
\hline Waist circumference (cm) & $80.58 \pm 10.21$ & $81.95 \pm 10.48$ & $78.99 \pm 9.65$ & $<0.001$ & & $74.56 \pm 7.62$ & $84.90 \pm 9.63$ & $<0.001$ \\
\hline BMI $\left(\mathrm{kg} / \mathrm{m}^{2}\right)$ & $27.32 \pm 4.36$ & $27.28 \pm 4.06$ & $27.34 \pm 4.67$ & 0.811 & & $25.13 \pm 3.11$ & $28.84 \pm 4.45$ & $<0.001$ \\
\hline BMI z score (SDS) & $2.03 \pm 0.51$ & $2.01 \pm 0.50$ & $2.06 \pm 0.52$ & 0.051 & & $2.00 \pm 0.39$ & $2.05 \pm 0.58$ & 0.802 \\
\hline HOMA-IR & $2.87 \pm 1.98$ & $2.75 \pm 2.00$ & $3.01 \pm 1.94$ & 0.001 & & $2.43 \pm 1.79$ & $3.44 \pm 1.94$ & $<0.001$ \\
\hline$|S|$ & $4.12 \pm 2.50$ & $4.23 \pm 2.18$ & $3.98 \pm 2.82$ & $<0.001$ & & $2.43 \pm 1.79$ & $3.50 \pm 2.95$ & $<0.001$ \\
\hline Fasting serum glucose (mg/dl) & $79.53 \pm 10.03$ & $80.38 \pm 9.85$ & $78.54 \pm 10.15$ & 0.001 & & $78.06 \pm 9.93$ & $79.53 \pm 10.03$ & $<0.001$ \\
\hline 2 h serum glucose $(\mathrm{mg} / \mathrm{dl})$ & $105.01 \pm 18.79$ & $105.41 \pm 18.94$ & $104.54 \pm 18.59$ & 0.367 & & $102.07 \pm 18.42$ & $107.04 \pm 18.77$ & $<0.001$ \\
\hline Fasting insulin $(\mu \mathrm{UI} / \mathrm{I})$ & $14.40 \pm 9.56$ & $13.67 \pm 10.03$ & $15.23 \pm 8.92$ & $<0.001$ & & $11.57 \pm 7.92$ & $16.37 \pm 10.10$ & $<0.001$ \\
\hline 2 h insulin $(\mu \mathrm{UI} / \mathrm{I})$ & $81.30 \pm 68.17$ & $72.28 \pm 59.32$ & $91.65 \pm 75.82$ & $<0.001$ & & $66.49 \pm 63.68$ & $91.50 \pm 69.32$ & $<0.001$ \\
\hline Uric acid (mg/dl) & $5.20 \pm 1.38$ & $5.28 \pm 1.45$ & $5.10 \pm 1.30$ & 0.058 & & $4.74 \pm 1.05$ & $5.52 \pm 1.49$ & $<0.001$ \\
\hline Total cholesterol (mg/dl) & $156.46 \pm 30.85$ & $158.63 \pm 32.82$ & $154.00 \pm 28.27$ & 0.005 & & $158.13 \pm 28.67$ & $155.30 \pm 32.25$ & 0.005 \\
\hline HDL-cholesterol (mg/dl) & $48.86 \pm 12.51$ & $49.88 \pm 13.78$ & $47.70 \pm 10.78$ & 0.004 & & $50.73 \pm 12.89$ & $47.56 \pm 12.08$ & 0.034 \\
\hline Triglycerides (mg/dl) & $76.33 \pm 41.02$ & $76.84 \pm 44.10$ & $75.74 \pm 37.01$ & 0.382 & & $71.39 \pm 39.30$ & $79.68 \pm 41.86$ & $<0.001$ \\
\hline ALT (IU/I) & $24.54 \pm 19.18$ & $26.86 \pm 23.68$ & $21.92 \pm 11.73$ & $<0.001$ & & $23.01 \pm 10.74$ & $25.61 \pm 23.30$ & 0.649 \\
\hline$\gamma-G T(I U / I)$ & $13.90 \pm 8.98$ & $15.02 \pm 10.57$ & $12.57 \pm 6.41$ & $<0.001$ & & $13.30 \pm 5.98$ & $14.30 \pm 10.52$ & 0.431 \\
\hline
\end{tabular}

Data are expressed as mean \pm SD or number and percentage. BMI body mass index, HOMA-IR homeostasis model assessment for insulin resistance, ISI insulin sensitivity index, $H D L$-cholesterol high-density lipoprotein cholesterol, $T G$ triglycerides, ALT alanine aminotransferase, $\gamma$-GT gamma-glutamyl transferase

Table 2 Mean values of serum uric acid $(\mathrm{mg} / \mathrm{dl})$ in children and adolescents with and without metabolic abnormalities

\begin{tabular}{|c|c|c|c|c|c|c|c|c|}
\hline \multicolumn{2}{|c|}{ Whole sample $(N=1364)$} & \multirow[t]{2}{*}{$p$ value } & \multicolumn{2}{|l|}{ Children $(N=560)$} & \multirow[t]{2}{*}{$p$ value } & \multicolumn{2}{|c|}{ Adolescents $(N=804)$} & \multirow[t]{2}{*}{$p$ value } \\
\hline $\begin{array}{l}\text { Normal Total } \\
\text { cholesterol } \\
(N=1112)\end{array}$ & $\begin{array}{l}\text { High Total } \\
\text { cholesterol } \\
(N=252)\end{array}$ & & $\begin{array}{l}\text { Normal Total } \\
\text { cholesterol } \\
(N=452)\end{array}$ & $\begin{array}{l}\text { High Total } \\
\text { cholesterol } \\
(N=108)\end{array}$ & & $\begin{array}{l}\text { Normal Total } \\
\text { cholesterol } \\
(N=660)\end{array}$ & $\begin{array}{l}\text { High Total } \\
\text { cholesterol } \\
(N=144)\end{array}$ & \\
\hline $5.2 \pm 1.4$ & $5.2 \pm 1.2$ & 0.7 & $4.7 \pm 1.0$ & $4.8 \pm 0.9$ & 0.6 & $5.5 \pm 1.5$ & $5.5 \pm 1.3$ & 0.7 \\
\hline $\begin{array}{l}\text { Normal } \\
\text { triglycerides } \\
(N=1277)\end{array}$ & $\begin{array}{l}\text { High } \\
\text { triglycerides } \\
(N=87)\end{array}$ & & $\begin{array}{l}\text { Normal } \\
\text { triglycerides } \\
(N=518)\end{array}$ & $\begin{array}{l}\text { High } \\
\text { triglycerides } \\
(N=42)\end{array}$ & & $\begin{array}{l}\text { Normal } \\
\text { triglycerides } \\
(N=759)\end{array}$ & $\begin{array}{l}\text { High } \\
\text { triglycerides } \\
(N=45)\end{array}$ & \\
\hline $4.9 \pm 1.4$ & $5.3 \pm 1.3$ & $<0.003$ & $4.4 \pm 1.0$ & $4.8 \pm 1.0$ & 0.03 & $5.3 \pm 1.5$ & $5.8 \pm 1.3$ & 0.9 \\
\hline $\begin{array}{l}\text { Normal HDL- } \\
\text { cholesterol } \\
(N=1214)\end{array}$ & $\begin{array}{l}\text { Low HDL- } \\
\text { cholesterol } \\
(N=150)\end{array}$ & & $\begin{array}{l}\text { Normal HDL- } \\
\text { cholesterol } \\
(N=516)\end{array}$ & $\begin{array}{l}\text { Low HDL- } \\
\text { cholesterol } \\
(N=44)\end{array}$ & & $\begin{array}{l}\text { Normal HDL- } \\
\text { cholesterol } \\
(N=699)\end{array}$ & $\begin{array}{l}\text { Low HDL- } \\
\text { cholesterol } \\
(N=105)\end{array}$ & \\
\hline $5.0 \pm 1.4$ & $5.5 \pm 1.4$ & $<0.001$ & $4.6 \pm 1.1$ & $4.9 \pm 0.9$ & 0.03 & $5.3 \pm 1.5$ & $5.8 \pm 1.5$ & 0.02 \\
\hline $\begin{array}{l}\text { Insulin sensitive } \\
(N=1155)\end{array}$ & $\begin{array}{l}\text { Insulin resistant } \\
(N=209)\end{array}$ & & $\begin{array}{l}\text { Insulin sensitive } \\
(N=519)\end{array}$ & $\begin{array}{l}\text { Insulin resistant } \\
(N=41)\end{array}$ & & $\begin{array}{l}\text { Insulin sensitive } \\
(N=636)\end{array}$ & $\begin{array}{l}\text { Insulin resistant } \\
(N=168)\end{array}$ & \\
\hline $5.1 \pm 1.3$ & $5.7 \pm 1.7$ & $<0.001$ & $4.7 \pm 1.0$ & $5 \pm 1.3$ & 0.5 & $5.5 \pm 1.5$ & $6 \pm 1.7$ & 0.5 \\
\hline $\begin{array}{l}\text { NFG } \\
(N=1323)\end{array}$ & $\begin{array}{l}\text { IFG } \\
(N=41)\end{array}$ & & $\begin{array}{l}\text { NFG } \\
(N=547)\end{array}$ & $\begin{array}{l}\text { IFG } \\
(N=13)\end{array}$ & & $\begin{array}{l}N F G \\
(N=776)\end{array}$ & $\begin{array}{l}\text { IFG } \\
(N=28)\end{array}$ & \\
\hline $5.2 \pm 1.4$ & $5.4 \pm 1.3$ & 0.4 & $4.7 \pm 1.0$ & $4.4 \pm 0.9$ & 0.4 & $5.5 \pm 1.5$ & $5.7 \pm 1.3$ & 0.9 \\
\hline $\begin{array}{l}\text { NGT } \\
(N=1311)\end{array}$ & $\begin{array}{l}\text { IGT } \\
(N=53)\end{array}$ & & $\begin{array}{l}\text { NGT } \\
(N=548)\end{array}$ & $\begin{array}{l}\text { IGT } \\
(N=12)\end{array}$ & & $\begin{array}{l}\text { NGT } \\
(N=763)\end{array}$ & $\begin{array}{l}\text { IGT } \\
(N=41)\end{array}$ & \\
\hline $5.1 \pm 1.2$ & $6.09 \pm 1.4$ & $<0.0001$ & $4.7 \pm 1.0$ & $5.3 \pm 1.1$ & 0.05 & $5.4 \pm 1.3$ & $6.2 \pm 1.5$ & 0.002 \\
\hline
\end{tabular}




\section{Children}

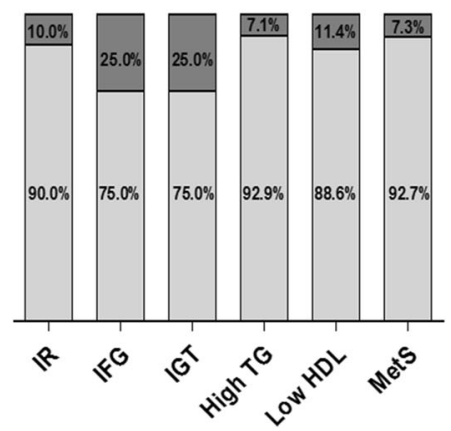

Adolescents

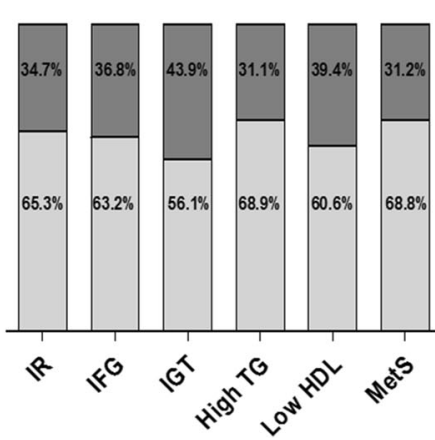

Lowest uric

acid quartiles

Highest uric

acid quartile

Fig. 1 Bars represents 100\% of cases with insulin resistance (IR), impaired fasting glucose (IFG), impaired glucose tolerance (IGT), high triglycerides (TG), low high densitity lipoprotein cholesterol (HDL), metabolic syndrome (MetS). Dark grey are cases with high uric acid above the highest quartile, light grey cases with uric acid in the lowest quartiles

abnormality and SUAlevels in the highest quartile of the distribution.

\section{Distribution of serum uric acid}

Table 3 reports SUA percentiles from the 5th to 95th in the population grouped by sex and age. In boys, SUA rose significantly from $>10-12$ years to $>12-14$ years $(p<0.05)$ and from $>12-14$ years to $>14$ years $(p<0.05)$. In girls, SUA increased significantly from $>8-10$ years to $>10-12$ years $(p<0.05)$ when its levels peaked. Significant sex-related differences were found by 10 years of age. Boys aged 10-12 years had significantly lower SUA than age-matched girls $(5.09 \pm 1.30$ vs. $5.41 \pm 1.36$; $p=0.002)$. Conversely, males had higher concentrations than girls at $12-14$ years of age (6.02 \pm 1.77 vs.5.17 $\pm 1.16 ; p<0.001)$ and onward $(6.99 \pm 0.99$ vs. $5.37 \pm 1.56 ; p<0.001)$.
High SUA (SUA $\geq 75^{\text {th }}$ percentile for age and sex) was observed in 246 patients (18\%), 98 children out of 560 (17.5\%) and 148 adolescents out of 804 (18.4\%).

\section{Correlations}

In the whole sample, there were statistically significant even weak correlations between SUA and age $(\rho=0.332)$, BMI $(\rho=0.416)$, BMI-z-score $(\rho=0.288)$, waist circumference $(\rho=0.467)$, HOMA-IR $(\rho=0.205)$; TG/HDL ratio $(\rho=0.218)$, fasting insulin $(\rho=0.238)$, ALT $(\rho=0.227)$ and ISI $(\rho=-0.239)(p<0.001$ for all). SUA was also correlated with $\gamma$-GT $(\rho=0.167)$, triglycerides $(\rho=0.165)$, HDL ( $\rho=-0.149)$, fasting glucose $(\rho=-0.107, p<0.001)$ and ISI $(\rho=-0.239) \gamma$-GT $(\rho=0.167)$, triglycerides $(\rho=0.165)$, HDL ( $\rho=-0.149)$, fasting glucose $(\rho=-0.107,(p<0.001$ for all).

Multivariable random-effect linear regression models demonstrated that waist circumference and age $(p<0.0001$ for both) are the variables most significantly predicting

Table 3 Distribution of serum uric acid (SUA, mg/dl) in overweight/obese patients by sex and age

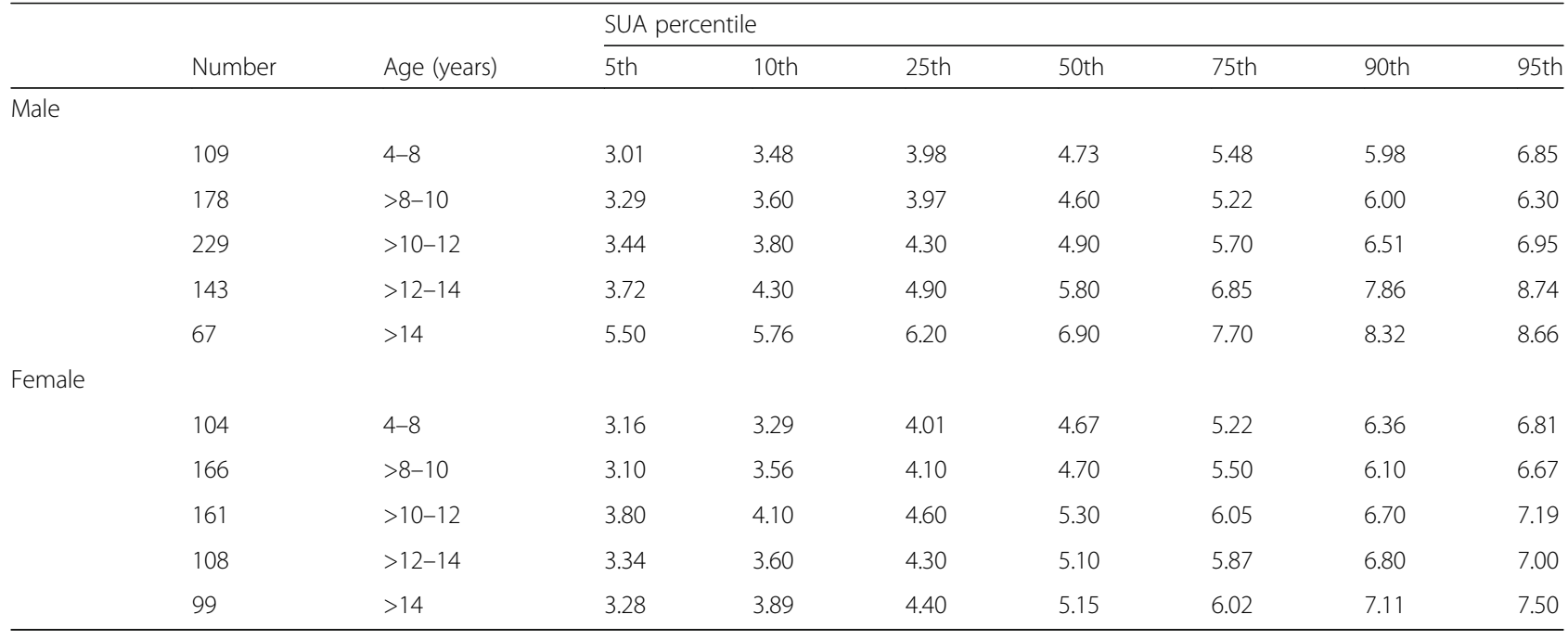


SUA levels, followed by triglycerides $(p=0.005)$ and $2 \mathrm{~h}$ glucose $(p=0.03)$ while HOMA-IR and BMI z-score did not predict SUA (Table 4).

In children with levels of SUA in the highest quartile, ORs for high triglycerides and atherogenic ratio were 4.145, (95\% CI 1.506-11.407; $p=0.009)$ and 2.74 (95\%CI $1.001-7.343 ; p=0.05)$, respectively. In adolescents, ORs were for insulin resistance 2.399 (95\%CI 1.4-4.113; $p<0.001)$; IFG 2.184 (95\%CI 0.877-5.441; $p=0.07)$; IGT 2.390, (95\% CI 1.405-4.063; $p=0.001)$; high triglycerides $1.8(95 \%$ CI $0.950-3.420, p=0.05)$ and atherogenic ratio 2.354, (95\%CI 1.490-3.718; $p<0.0001)$.

\section{Discussion}

Our study reports first age-and sex-specific percentiles of serum uric acid in a very large population of overweight/obese young Caucasians of Italian ancestry. It confirms associations of serum uric acid with waist circumference, triglycerides and glucose tolerance $(2 \mathrm{~h}$ glucose) in this population. Mean values of uric acid were significantly higher in children in the highest quartile of uric acid and both in children and adolescents with impaired glucose tolerance. Conversely, to belong to the highest quartile of uric acid was associated with an increased risk of presenting high triglycerides and atherogenic profile both in children and adolescents, while limited to adolescents there was an increased risk of presenting impaired fasting glucose and insulin resistance.

Gender-related trends of SUA concentrations overtime found in previous studies $[5,22,23]$ were confirmed in our sample. In a nationally representative population of 6768 youths aged 12 to 17 years from the National Health And Nutrition Examination Survey, NHANES [5], concentrations of SUA raised in the peripubertal period, peaked at the puberty (i.e. 10-12 years of age in females and 12-14 in males) and reached adult levels soon afterward. Gender-related differences in the peaking time almost certainly reflects the different tempo of the puberty onset [18] with delayed sexual and skeletal maturation in males [5]. After the puberty and throughout the adolescence SUA levels are lower in females likely because of the uricosuric effect of estrogens on the kidney tubular reabsorption of UA [22] and higher in males as possible effect of androgens [23]. In the later adolescence, i.e. ages 15 to 17 years for males and 13 to 17 years for females, BMI, skinfold thickness and blood pressure were determinants of SUA concentration stronger than sexual and somatic maturation [5]. Indeed, in our series of obese patients, mean values were higher than those found in normal-weight individuals as reported by the NHANES [22].

The study of Tang et al. [7] investigated SUA concentration in obese children and adolescents of Japanese nationality. The authors observed such an association between SUA and MetS also in children that they concluded hyperuricemia should be yet considered in early childhood as CVD risk factor [7]. Very recently Bassols et al. [14] found increased serum uric acid is associated with cIMT in asymptomatic prepubertal children highlighting the role of uric acid levels in the shaping of the cardiometabolic risk very early in childhood.

Our findings are in keeping with these reports. SUA was correlated with metabolic abnormalities both in children and in adolescents. Patients in the highest quartile of SUA levels were heavier and presented with worst lipid and insulin metabolism. The best correlation was seen between levels of SUA and waist circumference. Ford et al. [10] explored the association between SUA and components of the MetS in a nationally representative sample of 1370 adolescents aged 12-17 years from the NHANES 1999-2002. Patients with the full MetS had the highest SUA concentrations. The strongest association of SUA was seen with the waist circumference. In the general population of NHANES, a concentration of SUA $>5.7 \mathrm{mg} / \mathrm{dL}$ was associated with an adjusted OR for MetS of 14.79 (95\%CI 7.78-28.11) [10]. In our population of exclusive obese patients, this cut-off value corresponded to the $90^{\text {th }}$ percentile of SUA in obese males aged 8 years-old; to the $75^{\text {th }}$ in those aged 10 years-old; and to the $50^{\text {th }}$ and $10^{\text {th }}$ in males aged 12 and older than 14 years of age, respectively. In girls, it corresponds to the $90^{\text {th }}$ percentile in girls 6 years-old and to the $50^{\text {th }}$ $75^{\text {th }}$ in those by the age of 10 years onward. Hence, most of our obese patients had values of uric acids higher than 5.7 suggesting the co-occurrence of metabolic abnormalities. One of the limitations of the present study

Table 4 Age and metabolic parameters predicting levels of serum uric acid

\begin{tabular}{llllllll}
\hline & Model 1 & $p$ & Model 2 & $p$ & Model 3 & $p$ & Model 4 \\
\hline Age & & $0.092[0.053-0.130]$ & $<0.0001$ & $0.096[0.057-0.134]$ & $<0.0001$ & $0.096[0.058-0.134]$ & $<0.0001$
\end{tabular}

BMl z-score

HOMA-IR

$2 \mathrm{~h}$ glucose

$0.005[0.001-0.010] \quad 0.03$

Triglycerides

$0.003[0.001-0.006] \quad 0.001$

0.003 [0.001-0.005]

0.005

Waist circumference

0.049 [0.041-0.058]

$<0.0001 \quad 0.035[0.025-0.046]$

$<0.0001$

$0.031[0.020-0.041]$

$<0.0001$

0.030 [0.020-0.041]

$<0.0001$

Values are regression coefficients and $95 \%$ confidence intervals (in brackets) obtained from multivariable random-effect linear regression 
was the lack of Information on blood pressure. Therefore, we could not estimate prevalence of the full MetS and test the diagnostic accuracy of the $5.7 \mathrm{mg} / \mathrm{dL}$ cut-off as well as the association between SUA and blood pressure. It was a shame since uric acid contributes significantly to the pathogenesis of high blood pressure by activating the renin-angiotensin-aldosterone system directly at the vascular level and indirectly by inducing tubule-interstitial disease and consequent impaired baroreflex function [24]. High levels of uric acid in childhood were associated with high blood pressure at the same age [11]. The Bogalusa heat study demonstrated that high SUA in childhood predicts high blood pressure in adulthood [25] and, viceversa, features of MetS in childhood predict high SUA in adulthood [26].

Despite SUA is a CVD risk factor independent of IR [27], there is a clear relationship between SUA and hyperinsulinemia/IR levels. Hyperisulinemia/IR cause both increased production and reduced renal clearance of urate [28] while the amelioration of IR by low-energy diet or insulin sensitizing agents was found to decrease SUA levels [8]. Insulin favors renal urate reabsorption by stimulating the urate-anion exchanger URAT1 and/or the $\mathrm{Na}^{+}$-dependent anion cotransporter in brush border membranes of the renal proximal tubule [29]. In keeping with this pathogenic evidence, SUA levels paralleled insulin concentrations in our sample.

The strong association found by us and others $[10,13]$ with waist circumference confirms the strong link between uric acid, visceral adiposity and insulin resistance. In such interplay, increased consumption of dietary fructose may contribute [30] since fructose ingestion induces hepatic de novo lipogenesis, leading to increased visceral fat accumulation and, in turn, to worsened IR. One pathway to the production of serum uric acid, indeed, is via dietary fructose that activates the fructokinase metabolic system and upregulates de novo purine nucleotide synthesis in hepatocytes [31]. In that, SUA would act as marker of impaired adipogenesis [32] as further confirmed by associations observed between SUA and triglycerides levels, reduced HDL-cholesterol and, even better with an enhanced ratio of triglycerides to HDL-cholesterol after adjusting for covariates as seen in our population.

In addition to the lack of information about blood pressure, other important limitations must be acknowledged in our study, such as the absence of normal weight controls and information on pubertal stage.

In spite of these limitations, strengths of the present investigation were the large sample-size and the wide age-range that included preschoolers. Findings of relatively increased levels of uric acid already at this age supports the hypothesis of an early origin of cardiovascular disease associated with obesity putted forward by our research group [33].

\section{Conclusion}

In conclusion, our study confirms in a large population of Italian overweight/obese children and adolescents the association of high serum uric acid and metabolic abnormalities belonging to the MetS. The potential role of SUA as marker of increased CVD relies on these associations and seems independent of the degree of insulin resistance.

There is need of further research in large cohorts of children and adolescents better phenotyped in relation to their CVD to prove the cost-effectiveness of measuring routinely and monitoring overtime SUA in clinical settings.

\section{Abbreviations \\ ALT: Alanine aminotransferase; AUC: Area under curve; BMI: Body mass index; CRP: C-Reactive protein; CVD: Cardiovascular disease; HDL-cholesterol: High- density lipoprotein cholesterol; HOMA-IR: Homeostasis model assessment for insulin resistance; IFG: Impaired fasting glucose; IGT: Impaired glucose tolerance; IR: Insulin resistance; ISI: Insulin sensitivity index; MetS: Metabolic syndrome; OGTT: Oral glucose tolerance test; SUA: Serum uric acid; T2D: Type 2 diabetes; TG: Triglycerides; WBC: White blood cell count; WC: Waist circumference; $\gamma$-GT: Gamma-glutamyl transferase}

\section{Acknowledgements \\ None.}

\section{Funding}

BD received funds from the Italian Ministry of Health "Sviluppare profile genetici e trasferirli alla Sanità Pubblica in Italia".

\section{Availability of data and materials}

Raw data are available upon request to Melania Manco.

\section{Authors' contributions}

$R L, B D, M M$, conceived of the study, and participated in its design and coordination and drafted the manuscript. BS interpreted data, co-drafted and revised the manuscript, enrolled patients. ADF performed assays, contributed to data analysis and critical revised the manuscript. MS, CR, RWS, GSM enrolled patients, collected growth data and revised the manuscript for important intellectual content. All authors approved the final manuscript as submitted and agree to be accountable for all aspects of the work.

\section{Competing interests}

The authors declare that they have no competing interests.

\section{Ethics approval and consent to participate}

The study was in accordance with the Helsinki Declaration of 1975, as revised in 1983 and it was approved by the Ethics Committee of the Bambino Gesù Children's Hospital. Written informed consent was obtained from the child's parents/guardians, and patient's data were treated to guarantee privacy.

\section{Author details}

'Department of Laboratory Medicine, Bambino Gesù Children's Hospital, Rome, Italy. ${ }^{2}$ Scientific Directorate, Bambino Gesù Children's Hospital, Rome, Italy. ${ }^{3}$ Nutrition Unit, Bambino Gesù Children's Hospital, Rome, Italy.

${ }^{4}$ Scientific Directorate, Research Unit for Multifactorial Disease, Bambino Gesù

Children's Hospital, Rome, Italy.

Received: 12 October 2016 Accepted: 20 December 2016

Published online: 03 January 2017

\section{References}

1. Gagliardi AC, Miname MH, Santos RD. Uric acid: A marker of increased cardiovascular risk. Atherosclerosis. 2009;202:11-7.

2. Kanbay M, Segal M, Afsar B, Kang DH, Rodriguez-Iturbe B, Johnson RJ. The role of uric acid in the pathogenesis of human cardiovascular disease. Heart. 2013;99:759-66. 
3. Kivity S, Kopel E, Maor E, Abu-Bachar F, Segev S, Sidi Y, et al. Association of serum uric acid and cardiovascular disease in healthy adults. Am J Cardiol. 2013;111:1146-51.

4. Rodrigues TC, Maahs DM, Johnson RJ, Jalal DI, Kinney GL, Rivard C, et al. Serum uric acid predicts progression of subclinical coronary atherosclerosis in individuals without renal disease. Diabetes Care. 2010:33:2471-3.

5. Harlan WR, Cornoni-Huntley J, Leaverton PE. Physiologic determinants of serum urate levels in adolescence. Pediatrics. 1979;63:569-75.

6. Agamah ES, Srinivasan SR, Webber LS, Berenson GS. Serum uric acid and its relation to cardiovascular disease risk factors in children and young adults from a biracial community: the Bogalusa Heart Study. J Lab Clin Med. 1991;118:241-9.

7. Tang L, Kubota M, Nagai A, Mamemoto K, Tokuda M. Hyperuricemia in obese children and adolescents: the relationship with metabolic syndrome. Pediatr Rep. 2010;2:e12.

8. Tsunoda S, Kamide K, Minami J, Kawano Y. Decreases in serum uric acid by amelioration of insulin resistance in overweight hypertensive patients: effect of a low-energy diet and an insulin-sensitizing agent. Am J Hypertens. 2002;15:697-701.

9. Civantos Modino S, Guijarro de Armas MG, Monereo Mejias S, Montano Martinez JM, Iglesias Bolanos P, Merino Viveros M, et al. Hyperuricemia and metabolic syndrome in children with overweight and obesity. Endocrinol Nutr. 2012;59:533-8.

10. Ford ES, Li C, Cook S, Choi HK. Serum concentrations of uric acid and the metabolic syndrome among US children and adolescents. Circulation. 2007;115:2526-32

11. Loeffler LF, Navas-Acien A, Brady TM, Miller 3rd ER, Fadrowski JJ. Uric acid level and elevated blood pressure in US adolescents: National Health and Nutrition Examination Survey, 1999-2006. Hypertension. 2012;59:811-7.

12. Pacifico L, Cantisani V, Anania C, Bonaiuto E, Martino F, Pascone R, et al. Serum uric acid and its association with metabolic syndrome and carotid atherosclerosis in obese children. Eur J Endocrinol. 2009;160:45-52.

13. Ishiro M, Takaya R, Mori Y, Takitani K, Kono Y, Okasora K, et al. Association of uric acid with obesity and endothelial dysfunction in children and early adolescents. Ann Nutr Metab. 2013;62:169-76.

14. Bassols J, Martínez-Calcerrada JM, Prats-Puig A, Carreras-Badosa G, DíazRoldán F, Osiniri I, Riera-Pérez E, de Zegher F, Ibáñez L, López-Bermejo A. Uric acid, carotid intima-media thickness and body composition in prepubertal children. Pediatr Obes. 2016;11(5):375-82.

15. Sun HL, Pei D, Lue KH, Chen YL. Uric Acid Levels Can Predict Metabolic Syndrome and Hypertension in Adolescents: A 10-Year Longitudinal Study. PLoS One. 2015;10(11):e0143786.

16. Luciano R, Barraco GM, Muraca M, Ottino S, Spreghini MR, Sforza RW, et al. Biomarkers of Alzheimer disease, insulin resistance, and obesity in childhood. Pediatrics. 2015;135:1074-81.

17. Cacciari E, Milani S, Balsamo A, Spada E, Bona G, Cavallo L, Cerutti F, Gargantini L, Greggio N, Tonini G, Cicognani A. Italian cross-sectional growth charts for height, weight and BMI (2 to $20 \mathrm{yr}$ ). J Endocrinol Invest. 2006;29(7):581-93.

18. National High Blood Pressure Education Program Working Group on High Blood Pressure in Children and Adolescents. The fourth report on the diagnosis, evaluation and treatment of high blood pressure in children and adolescents. Pediatrics. 2004;114(Suppl 4th Report):555-76.

19. Manco M, Grugni G, Di Pietro M, Balsamo A, Di Candia S, Morino GS, et al. Triglycerides-to-HDL cholesterol ratio as screening tool for impaired glucose tolerance in obese children and adolescents. Acta Diabetol. 2016;53:493-8.

20. Di Bonito P, Valerio G, Grugni G, Licenziati MR, Maffeis C, Manco M, et al. Comparison of non-HDL-cholesterol versus triglycerides-to-HDL-cholesterol ratio in relation to cardiometabolic risk factors and preclinical organ damage in overweight/obese children: the CARITALY study. Nutr Metab Cardiovasc Dis. 2015;25:489-94.

21. Shashaj B, Luciano R, Contoli B, Morino GS, Spreghini MR, Rustico C, et al. Reference ranges of HOMA-IR in normal-weight and obese young Caucasians. Acta Diabetol. 2016;53:251-60.

22. Stapleton FB, Linshaw MA, Hassanein K, Gruskin AB. Uric acid excretion in normal children. J Pediatr. 1978;92:911-4.

23. Denzer C, Muche R, Mayer H, Heinze E, Debatin KM, Wabitsch M. Serum uric acid levels in obese children and adolescents: linkage to testosterone levels and pre-metabolic syndrome. J Pediatr Endocrinol Metab. 2003;16:1225-32.

24. Oparil S, Zaman MA, Calhoun DA. Pathogenesis of hypertension. Ann Intern Med. 2003;139:761-76
25. Alper Jr AB, Chen W, Yau L, Srinivasan SR, Berenson GS, Hamm LL. Childhood uric acid predicts adult blood pressure: the Bogalusa Heart Study. Hypertension. 2005;45:34-8.

26. Muntner P, Srinivasan S, Menke A, Patel DA, Chen W, Berenson G. Impact of childhood metabolic syndrome components on the risk of elevated uric acid in adulthood: the Bogalusa Heart Study. Am J Med Sci. 2008:335:332-7.

27. Facchini F, Chen YD, Hollenbeck CB, Reaven GM. Relationship between resistance to insulin-mediated glucose uptake, urinary uric acid clearance, and plasma uric acid concentration. JAMA. 1991;266:3008-11

28. Muscelli E, Natali A, Bianchi S, Bigazzi R, Galvan AQ, Sironi AM, et al. Effect of insulin on renal sodium and uric acid handling in essential hypertension. Am J Hypertens. 1996;9:746-52.

29. Enomoto A, Kimura H, Chairoungdua A, Shigeta Y, Jutabha P, Cha SH, et al. Molecular identification of a renal urate anion exchanger that regulates blood urate levels. Nature. 2002;417:447-52.

30. Lin WT, Chan TF, Huang HL, Lee CY, Tsai S, Wu PW, et al. Fructose-Rich Beverage Intake and Central Adiposity, Uric Acid, and Pediatric Insulin Resistance. J Pediatr. 2016;171:90-6.e1.

31. Stanhope KL, Schwarz JM, Keim NL, Griffen SC, Bremer AA, Graham JL, et al. Consuming fructose-sweetened, not glucose-sweetened, beverages increases visceral adiposity and lipids and decreases insulin sensitivity in overweight/obese humans. J Clin Invest. 2009;119:1322-34.

32. Matsuura F, Yamashita S, Nakamura T, Nishida M, Nozaki S, Funahashi T, et al. Effect of visceral fat accumulation on uric acid metabolism in male obese subjects: visceral fat obesity is linked more closely to overproduction of uric acid than subcutaneous fat obesity. Metabolism. 1998;47:929-33.

33. Shashaj B, Bedogni G, Graziani MP, Tozzi AE, DiCorpo ML, Morano D, et al. Origin of cardiovascular risk in overweight preschool children: a cohort study of cardiometabolic risk factors at the onset of obesity. JAMA Pediatr. 2014:168:917-24.

\section{Submit your next manuscript to BioMed Central and we will help you at every step:}

- We accept pre-submission inquiries

- Our selector tool helps you to find the most relevant journal

- We provide round the clock customer support

- Convenient online submission

- Thorough peer review

- Inclusion in PubMed and all major indexing services

- Maximum visibility for your research

Submit your manuscript at www.biomedcentral.com/submit
) Biomed Central 